\title{
Spatial and temporal variability in vegetation cover of Mongolia and its implications
}

\author{
Sumiya VANDANDORJ ${ }^{1}$, Batdelger GANTSETSEG ${ }^{1}$, Bazartseren BOLDGIV ${ }^{2 *}$ \\ ${ }^{1}$ Institute of Meteorology, Hydrology and Environment, Ulaanbaatar 210646, Mongolia; \\ ${ }^{2}$ Ecology Group, Department of Biology, School of Arts and Sciences, National University of Mongolia, Ulaanbaatar 14201, Mongolia
}

\begin{abstract}
In this paper, we attempted to determine the most stable or unstable regions of vegetation cover in Mongolia and their spatio-temporal dynamics using Terra/MODIS Normalized Difference Vegetation Index (NDVI) dataset, which had a 250-m spatial resolution and comprised 6 periods of 16-day composited temporal resolution data (from 10 June to 13 September) for summer seasons from 2000 to 2012. We also used precipitation data as well as biomass data from 12 meteorological stations located in 4 largest natural zones of Mongolia. Our study showed that taiga and forest steppe zones had relatively stable vegetation cover because of forest characteristics and relatively high precipitation. The highest coefficient of variation (CV) of vegetation cover occurred frequently in the steppe and desert steppe zones, mainly depending on variation of precipitation. Our results showed that spatial and temporal variability in vegetation cover (NDVI or plant biomass) of Mongolia was highly dependent on the amount, distribution and CV of precipitation. This suggests that the lowest inter-annual CV of NDVI can occur during wet periods of growing season or in high precipitation regions, while the highest inter-annual CV of NDVI can occur during dry periods and in low precipitation regions. Although the desert zone received less precipitation than other natural zones of the country, it had relatively low variation compared to the steppe and desert steppe, which could be attributed to the very sparse vegetation in the desert.
\end{abstract}

Keywords: vegetation cover; MODIS NDVI; natural zones; seasonal dynamics; stability; Mongolia

Citation: Sumiya VANDANDORJ, Batdelger GANTSETSEG, Bazartseren BOLDGIV. 2015. Spatial and temporal variability in vegetation cover of Mongolia and its implications. Journal of Arid Land, 7(4): 450-461. doi: 10.1007/s40333-015-0001-8

The inter- or intra-annual variation in vegetation cover and aboveground net primary production (ANPP) are affected by the amount and distribution patterns of precipitation (Nicholson et al., 1990; Oesterheld et al., 2001; Wang et al., 2003; Xin et al., 2008). ANPP is a major component of energy that drives ecosystem processes (Webb et al., 1983). In an area that has lower inter-annual variability of aboveground plant biomass, plant species richness is higher (Tilman, 1996) because populations would be relatively stable and extinction rates due to population fluctuations would be low (Sanders and Hessler, 1969; Oindo and Skidmore, 2002). In the southern Mongolian dryland, the main gradient in plant community composition is closely correlated to environmental variables including altitude, precipitation and NPP (von Wehrden and Wesche, 2007).

The remote sensing technique is one of a number of suitable tools used to determine the variability of vegetation cover for such an expansive territory as Mongolia. In the last few decades, scientists have focused on Mongolian vegetation issues using the remote sensing approach. The results have shown detectable decreases in biomass, which could be attributed to decreasing precipitation, increasing temperatures, dramatically increasing goat populations, wildfires in the Eastern steppe (Liu et al., 2013), land degradation and land use conversion near the densely populated

\footnotetext{
*Corresponding author: Bazartseren BOLDGIV (E-mail: boldgiv@num.edu.mn, boldgiv@gmail.com) 
cities of Ulaanbaatar and Darkhan (Hirano et al., 2006). In addition, a significant negative relationship between the NDVI and the Land Surface Temperature (LST) has been found for the desert steppe and steppe ecosystems (Karnieli et al., 2006). The desert steppe is considered particularly vulnerable to desertification (Lin et al., 2006; Batbold and Natsagdorj, 2013). To our knowledge, there has been no study on inter-annual variability of vegetation cover based on coefficient of variation (CV) of NDVI for whole Mongolia, but there have been some studies focusing on this aspect in different regions of the world (Fang et al., 2001; Barbosa et al., 2006; Bai et al., 2008).

The eastern steppe and south-eastern desert steppe of Mongolia are becoming hotspots of decreasing biomass and desertification (Lin et al., 2006; Batbold and Natsagdorj, 2013; Liu et al., 2013). And it is an important habitat for such wildlife species as the Mongolian gazelle (Procapra gutturosa; Mueller et al., 2008), and then the Mongolian gazelle strongly competes with livestock, mostly sheep and goats, for food sources (Campos-Arceiz et al., 2004; Yoshihara et al., 2008). Furthermore, the steppe vegetation is the main food source for $45.1 \times 10^{6}$ domestic livestock, which in turn directly affects the livelihood of about $15 \times 10^{4}$ livestock herding families (NSO, 2013), and other wild herbivore species, and indirectly affects non-herder families that are consumers of livestock products in Mongolia. Therefore, it is important to understand the patterns of inter-annual variability of vegetation cover or biomass for natural resource management, ecosystem sustainability and biodiversity conservation.

The objectives of our study were: (1) to determine stable and unstable regions for vegetation cover using the NDVI data for Mongolia; (2) to identify the effect of precipitation on the CV of NDVI and plant biomass; and (3) to determine differences among natural zones and understand spatial and temporal variation in $\mathrm{CV}$ of NDVI.

\section{Materials and methods}

\subsection{Data sources and study area}

The primary data source was the Terra/MODIS NDVI, which has 250-m resolution and 16-day composite data for the entire country of Mongolia between 2000 and 2012. These data were downloaded from the United States Geological Survey’s (USGS) opensource site (http://e4ftl01.cr.usgs.gov/MOLT/MOD13 Q1.005/). We selected six Julian days, namely days 161, 177, 193, 209, 225 and 241 that cover the summer season. Each Julian day number represented the starting date of the 16-day composited NDVI. As a result, our summer season NDVI data ranged from 10 June to 13 September. These Julian days were respectively represented as periods 1 through 6 in this study.

Mongolia spans over six main natural zones: high mountains that cover $3.6 \%$ of the country; taiga $4.5 \%$, forest steppe $15.2 \%$, steppe $34.2 \%$, desert steppe 23.4\% and desert 19.1\% (Dash, 2000). For this study, we randomly selected three meteorological stations based on biomass data availability for each of the four largest natural zones, making a total of 12 meteorological stations to validate the CV of NDVI (Fig. 1).

Every summer season, the Institute of Meteorology, Hydrology and Environment (IMHE) of Mongolia measures plant biomass every 10 days from both inside and outside of a fenced area around each meteorological station. The fenced area is $25 \mathrm{~m} \times 25 \mathrm{~m}$ in forest steppe and steppe, while it is $50 \mathrm{~m} \times 50 \mathrm{~m}$ in desert steppe and desert zones. For the period of 2000-2012, daily precipitation (collected by IMHE) and two kinds of plant biomass data (from inside and outside the fence) from the 12 meteorological stations were used to determine the relationship between the variability of the meteorological data and the NDVI (Table 1). Plant biomass was taken from fenced (ungrazed) areas on 24 August and from open (grazed) areas on 25 August of every year, because plant growth usually ends at this time of year. Plant biomass $\left(\mathrm{g} / \mathrm{m}^{2}\right)$ represented an average of 4 replicates of biomass sampling from $1 \mathrm{~m} \times 1 \mathrm{~m}$ areas in both cases.

\subsection{Data analysis}

\subsubsection{Coefficient of variation mapping}

We produced six maps of CV for whole Mongolia based on the NDVI data between 2000 and 2012, using standard CV formula (Eq. 1). Each raster map represented different periods (Period 1 through Period 6 ) of the main season for vegetation growth in Mongolia. 


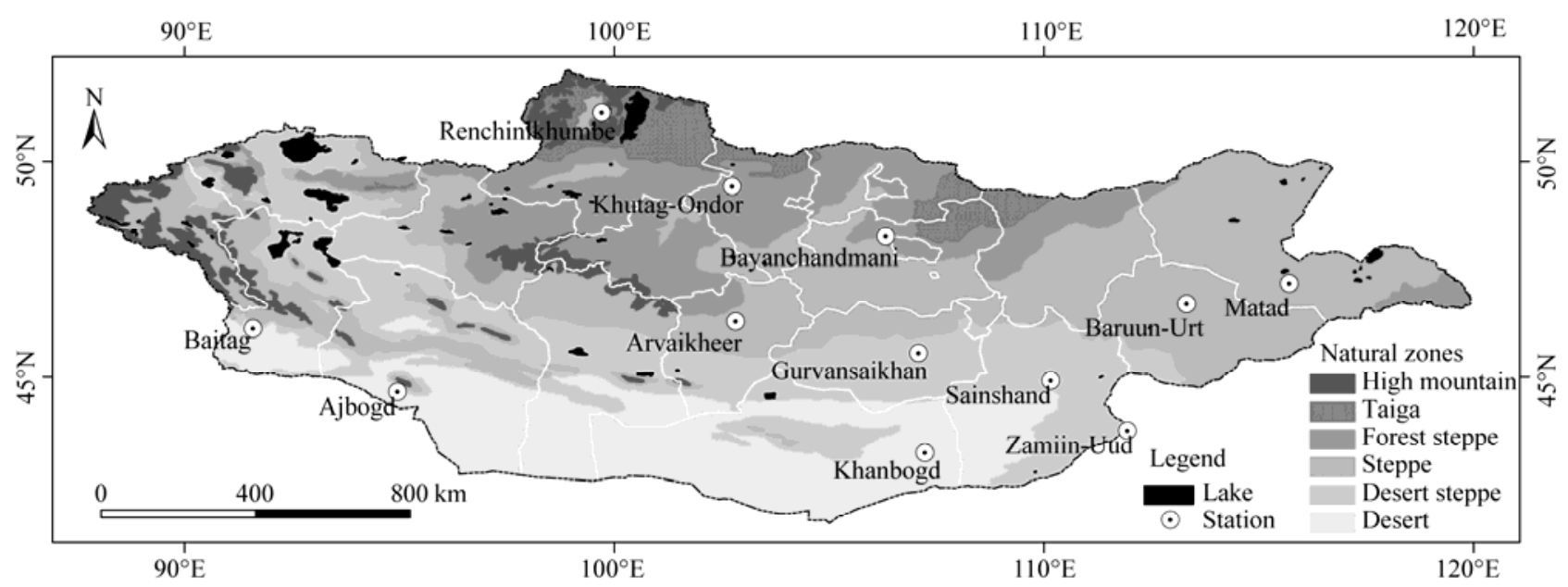

Fig. 1 Twelve meteorological stations selected for ground data and their locations in the natural zones of Mongolia

Table 1 Mean annual precipitation (MAP), annual mean temperature from 2000 to 2012 and corresponding natural zones of the 12 meteorological stations

\begin{tabular}{cllcc}
\hline No. & Station name & Natural zone & Mean annual precipitation $(\mathrm{mm})$ & Annual mean temperature $\left({ }^{\circ} \mathrm{C}\right)$ \\
\hline 1 & Bayanchandmani & Forest steppe & 259.45 & 0.28 \\
2 & Khutag-Ondor & Forest steppe & 298.00 & -0.11 \\
3 & Renchinlkhumbe & Forest steppe & 281.22 & -6.51 \\
4 & Baruun-Urt & Steppe & 173.12 & 1.67 \\
5 & Matad & Steppe & 215.12 & 1.92 \\
6 & Arvaikheer & Steppe & 209.47 & 2.03 \\
7 & Gurvansaikhan & Desert steppe & 91.59 & 4.15 \\
8 & Zamiin-Uud & Desert steppe & 118.43 & 4.77 \\
9 & Sainshand & Desert steppe & 103.80 & 5.54 \\
10 & Ajbogd & Desert & 50.98 & 5.76 \\
11 & Baitag & Desert & 83.34 & 2.85 \\
12 & Khanbogd & Desert & 108.49 & 7.76 \\
\hline
\end{tabular}

$$
C V_{(\mathrm{NDVI}) i}=\frac{\sigma_{(\mathrm{NDVI}) i}}{\mu_{(\mathrm{NDVl}) i, 2000-2012}} .
$$

Where $i$ represents period, $\sigma$ is standard deviation of $i^{\text {th }}$ period, and $\mu$ is NDVI mean of $i^{\text {th }}$ period between 2000 and 2012.

After this, the six CV maps were averaged. Each of $\mathrm{CV}$ maps of six periods and their averages were classified into 10 categories, respectively, for determining the spatial distribution of CV of NDVI in Mongolia. Furthermore, only the average CV map was classified by $5 \%$ into $20 \mathrm{CV}$ levels for more information and it was used to create a graph of CV frequency. Based on this frequency graph, we selected cut-off values for low and high variation of NDVI. Coefficients of variation values of $0-10 \%$ (low variation) and $>40 \%$ (high variation) were extracted respectively from the six raster maps of the $\mathrm{CV}$, and were overlapped into a single raster to create a frequency map. In other words, if the value of the $\mathrm{CV}$ was lower than $10 \%$ or more than $40 \%$ for the six periods in the same grid, the grid was considered more stable or unstable, respectively, for NDVI during the whole summer.

\subsubsection{Effect of precipitation on the CV of NDVI and plant biomass}

Coefficients of variation of plant biomass, monthly and yearly precipitation of the twelve stations between 2000 and 2012 were calculated. Then regression and 
correlation analyses were used to determine the relationship among the CV of NDVI, precipitation and plant biomass.

1.2.3 Seasonal dynamics, differences and changes in the area of NDVI's CV levels among different natural zones

An average CV of NDVI was extracted from a $20 \mathrm{~km} \times$ $20 \mathrm{~km}$ area at each of the 12 meteorological stations for all six periods of the CV maps. The CV values were averaged again later by stations that were located in the same natural zone for each period for determining the seasonal dynamics of the NDVI's CV in the four different natural zones. We used a one-way ANOVA and the Tukey-Kramer HSD analysis to test the differences among the four largest natural zones of Mongolia based on the values of all six periods, which were extracted from the $20 \mathrm{~km} \times 20 \mathrm{~km}$ grids near the 12 meteorological stations.

An additional issue was the seasonal dynamics of an area for each CV level of NDVI in all six natural zones of Mongolia. We extracted each of the six raster maps from natural zones. Then we classified each extraction which make up $100 \%$ of an area into $10 \mathrm{CV}$ levels (0-5\%, 5\%-10\%, 10\%-15\%, 15\%-20\%, 20\%25\%, 25\%-30\%, 30\%-35\%, 35\%-40\%, 40\%-45\% and $>45 \%$ ) based on the $\mathrm{CV}$ values.

\section{Results}

\subsection{Distribution maps of $\mathbf{C V}$}

Six coefficient of variation of NDVI maps, representing six different summer periods, were produced respectively. An average CV of those six periods was also shown in Fig. 2. In Period 1, the highest CV occurred around high mountains, such as western Hövsgöl, Altai and Gobi-Altai, and also the northeastern steppe. After this period, the $\mathrm{CV}$ of high mountains decreased, though the northeastern steppe still had a high CV until Period 2. Periods 3 and 4 were very similar: the CV of NDVI reached its peak in the steppe and desert steppe. In addition, CV values were diverged to the highest or lowest values during these periods more clearly. By the end of summer, or periods 5 and 6 , the difference of the CVs gradually decreased.
The frequency of such values within the CV levels was extracted from the average $\mathrm{CV}$ map and it is shown in Fig. 3. Approximately 4\% of the territory had extremely high (more than 95\%) variation cover, but this area was clearly prohibitive to plant growth, including, for example, in the areas of lakes and glaciers. The highest frequency value of the $\mathrm{CV}$ was $20 \%-25 \%$, following $25 \%-30 \%$ and $15 \%-20 \%$. We selected some cut-off values based on the frequency graph shown in Fig. 3, for example, $10 \%$ and $40 \%$ as the threshold values of the lowest and highest $\mathrm{CV}$ of NDVI. If we excluded unsuitable areas (i.e. areas with more than a $95 \%$ of $\mathrm{CV}$ ) for vegetation, the lowest (0-10\%) and higher (40\%-95\%) CVs occupy approximately $15 \%$ of Mongolia, respectively.

The results of the lowest (0-10\%) and higher $(>40 \%) \mathrm{CV}$ of NDVI of the six time-series showed that eastern Hövsgöl; some parts Arkhangai; the northern parts of Bulgan, Töv and Khentii; and the southern parts of Gobi-Altai, Bayankhongor and Omnogobi provinces were more stable (CV values $<10 \%$ ) during the whole summer. The far east of Dornod, southern Hövsgöl and some parts of Arkhangai and Zavkhan provinces were also stable, but not for the whole summer (Fig. 4). These stable areas in vegetation cover were either forest, taiga forest or just very sparsely vegetated desert areas.

The western part of Hövsgöl, the northern parts of Sukhbaatar, Dornogobi and Dundgobi; the southern parts of Bayankhongor, Gobi-Altai and Khovd, and a very small area of southern Töv and Khentii provinces showed high CVs for vegetation cover for some of the periods.

\subsection{Effect of precipitation on the CV of NDVI and plant biomass}

The mean annual precipitation (MAP) was negatively correlated with the $\mathrm{CV}$ of annual precipitation ( $r=$ $-0.72, P<0.01)$. The coefficient of variation of NDVI in Period 5 was negatively affected by the MAP ( $r=$ $-0.53)$ and a positive relationship was found between the CV of annual ( $r=0.70, P<0.05)$ and July ( $r=0.69$, $P<0.05)$ precipitation. The $\mathrm{CV}$ of total precipitation in July affected both of the biomasses inside and outside fences (Fig. 5). The biomasses were highly correlated with each other. 


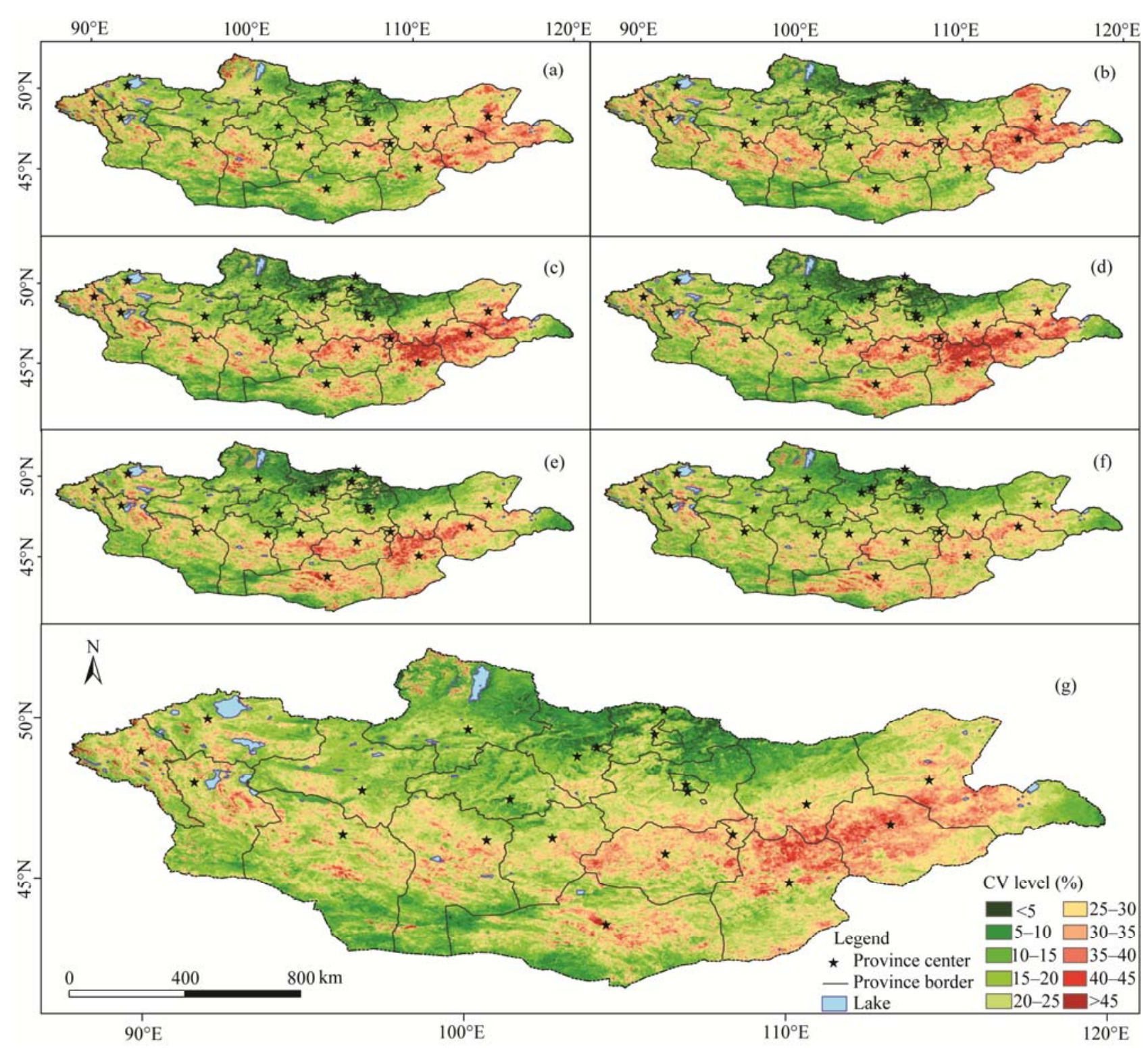

Fig. 2 The seasonal distribution of the coefficient of variation (CV) of Normalized Difference Vegetation Index (NDVI) and its general pattern in Mongolia. Maps a-f represent exact periods (Period1-Period 6) of growing season, respectively, and map g represents the average of maps a-f.

The CV of NDVI was highly dependent on the amount, geographical distribution and variation of precipitation (Fig. 6). For example, the CV of NDVI in Period 6 was negatively affected by mean annual precipitation $(r=-0.61, \quad P<0.05)$ and a positive relationship was found between the CV of annual ( $r=$ $0.85, P<0.01)$ and July $(r=0.83, P<0.01)$ precipitation.

\subsection{Seasonal dynamics, differences and changes in the area of NDVI's CV levels among different natural zones}

Average CV values of NDVI were extracted from the
$20 \mathrm{~km} \times 20 \mathrm{~km}$ areas at 12 stations, and they were averaged again by natural zones. The forest steppe was almost stable for the whole summer as it had a relatively low CV. The dynamic patterns of the steppe and desert zones were similar across the six periods, but the steppe kept a higher average CV of about 10\% over the desert. The steppe and desert zones showed their highest values of CV in Period 3, while the desert steppe reached its highest CV in Period 4 (Fig. 7).

The average NDVI values of forest steppe and desert zones were significantly different and different from the other two natural zones. But there was 


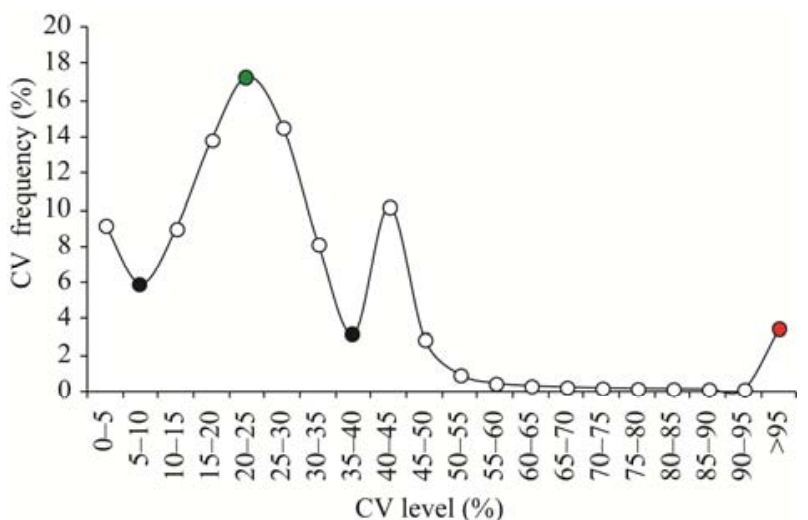

Fig. 3 The relationship between CV frequency and CV level in Mongolia. The black dots are cutoff values for the lowest and highest $\mathrm{CV}$ values. The green dot represents the most frequently observed value. The red dot represents the highest variation of NDVI, but was considered to be an unsuitable area for vegetation. no difference in the average CV of NDVI extracted from the $20 \mathrm{~km} \times 20 \mathrm{~km}$ grids between the steppe and desert steppe, according to one-way ANOVA and Tukey-Kramer HSD pair-wise mean comparisons for all stations of natural zones (Table 2). Two-way ANOVA was used to check the interaction between natural zones and the periods from 1 to 6 in the CV values of NDVI, but there was no significant interaction.

Almost half of the territory of Mongolia had a CV of $15 \%-30 \%$ for vegetation cover during the growth season. In a detailed graph, we showed the seasonal dynamics of the areas with different levels of CV and in different natural zones (Fig. 8). The area which had a CV level of $>45 \%$ in Period 1 took up a bigger area than other periods in high mountains because of snow coverage.

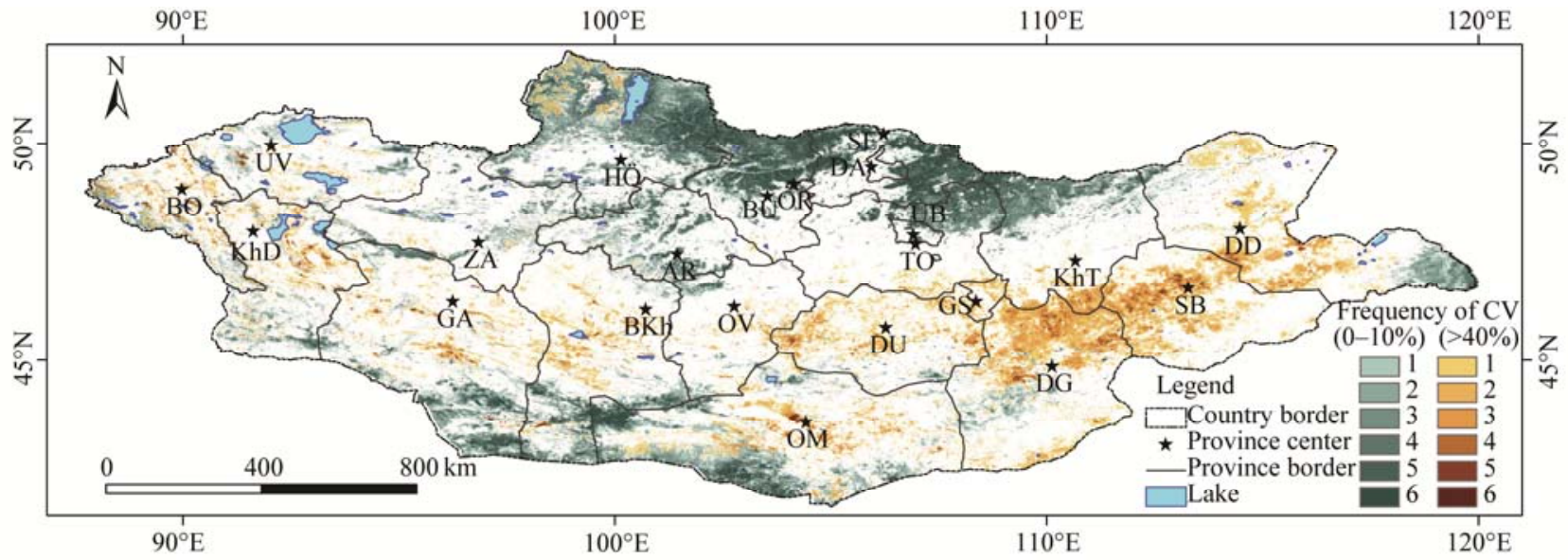

Fig. 4 A frequency map of the lowest (0-10\%) and highest (>40\%) CV of NDVI for the six periods. Dark green and orange colors indicate frequency of NDVI's CV below than $10 \%$ and more than $40 \%$, respectively. The numbers between 1 and 6 represent the time of occurrence of certain NDVI's CV in six periods of growing season. The white color on the frequency map indicates the regions that have not shown values of $0-10 \%$ and more than $40 \%$ during the six periods. The abbreviations indicate the names of each province (AR, Arkhangai; BKh, Bayankhongor; BO, Bayan-Olgii; BU, Bulgan; DA, Darkhan; DD, Dornod; DG, Dornogobi; DU, Dundgobi; GA, Gobi-Altai; GS, Gobisumber; KhD, Khovd; KhT, Khentii; HÖ, Hövsgöl; OM, Omnogobi; OV, Ovorkhangai; OR, Orkhon; SB, Sukhbaatar; SE, Selenge; TO, Töv; UB, Ulaanbaatar; UV, Uvs; ZA, Zavkhan).

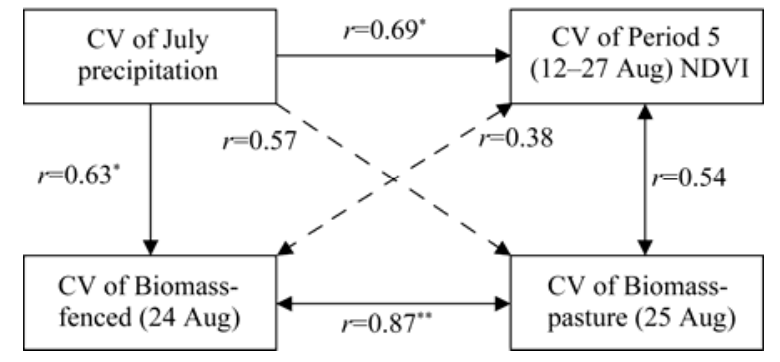

Fig. 5 The relationship between biomass and the NDVI in August and the effect of $\mathrm{CV}$ of July precipitation on both of them. * and ${ }^{* *}$ indicate significance at $P<0.05$ and $P<0.01$ levels, respectively.
Most of the areas (about 62\%) of the taiga had relatively low variation (CV of $0-10 \%$ ) during the summer season. Areas which had CVs of NDVI of more than $20 \%$ in the high mountains and forest steppe, and more than $15 \%$ in the taiga, decreased during the summer. The areas which had CVs of NDVI of $0-10 \%$ in the forest steppe and more than $30 \%$ in the steppe and desert steppe reached maximum area in mid-summer. The areas with CV values of 5\%-20\% increased in the steppe and decreased in desert steppe and desert during the summer. The areas which 


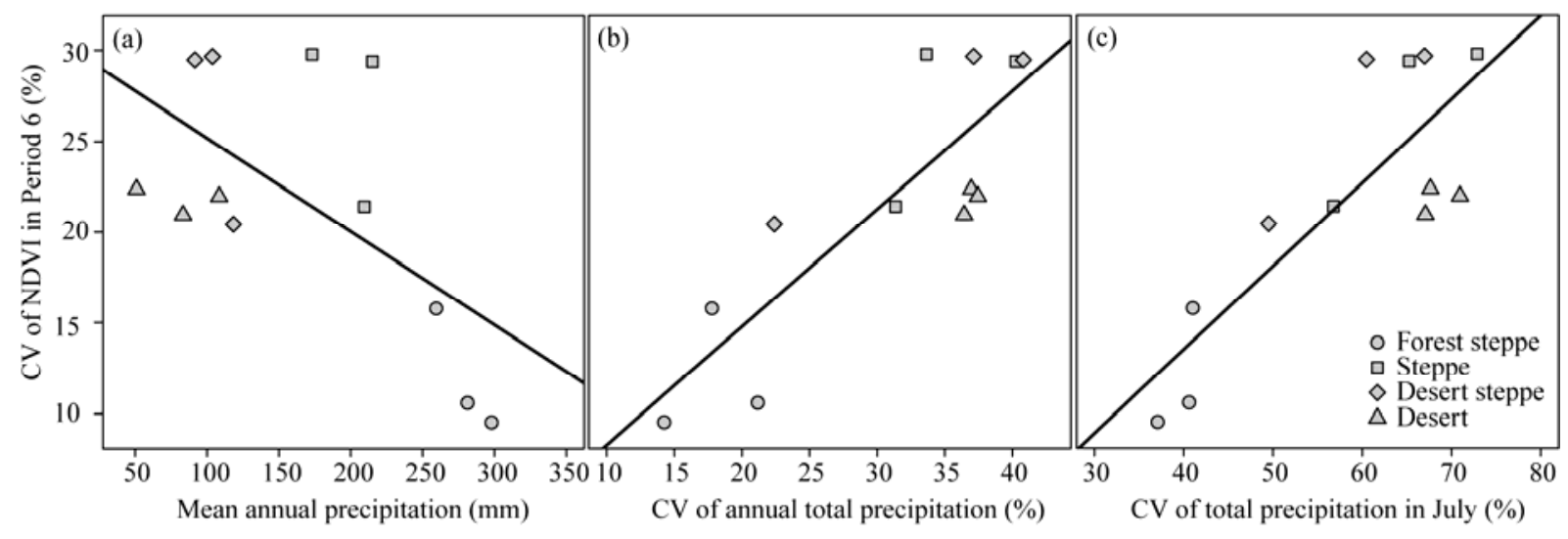

Fig. 6 Correlations between the CV of NDVI of Period 6 and mean annual precipitation (a), the CV of total annual precipitation (b) and the $\mathrm{CV}$ of July precipitation (c) for the 12 meteorological station locations

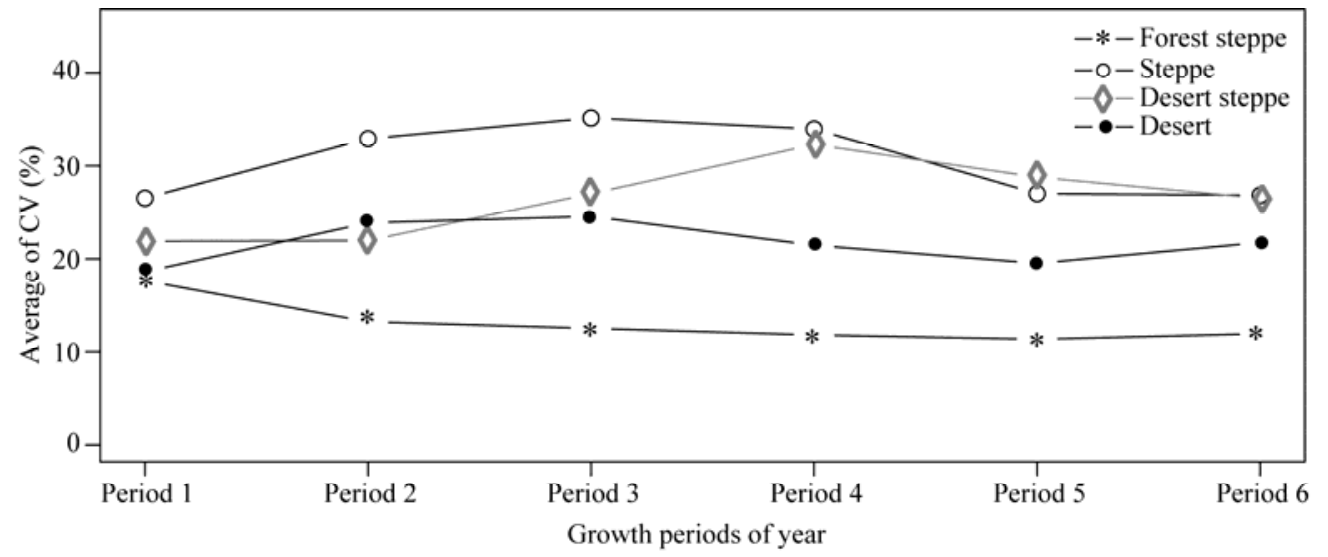

Fig. 7 The seasonal dynamics of CV values in four major natural zones of Mongolia

Table 2 Difference of average CVs of NDVI between natural zones

\begin{tabular}{lcccc}
\hline & Forest steppe & Steppe & Desert steppe & Desert \\
\hline Forest steppe & & & & \\
Steppe & $<0.0001$ & & & \\
Desert steppe & $<0.0001$ & 0.0922 & & \\
Desert & $<0.0001$ & $<0.0001$ & 0.0299 &
\end{tabular}

Note: The P-values were calculated using one-way ANOVA, Tukey-Kramer HSD pair-wise mean comparisons based on the average NDVI value that was extracted from the $20 \mathrm{~km} \times 20 \mathrm{~km}$ area in the selected stations.

had a CV value of more than $20 \%$ increased in the desert for the whole summer.

\section{Discussion}

In this paper we determined the most stable or unstable regions of Mongolia for vegetation cover and its spatio-temporal dynamics using Terra/MODIS Normalized Difference Vegetation Index (NDVI) data and ground-based data on plant biomass for summer seasons between 2000 and 2012. Our study showed that taiga and forest steppe zones had relatively stable vegetation cover. In contrary, the highest CV of NDVI occurred frequently in the steppe and desert steppe zones, depending on variation of precipitation. In other words, the spatial and temporal variability in vegetation cover (NDVI or biomass) of Mongolia was highly dependent on the amount, distribution and CV of precipitation in our study.

There have been similar studies from other regions of the world (Fang et al., 2001; Barbosa et al., 2006). The greatest range of annual net primary production (ANPP) was recorded in warm, herbaceous-dominated 
Sumiya VANDANDORJ et al.: Spatial and temporal variability in vegetation cover of Mongolia and its implications

457
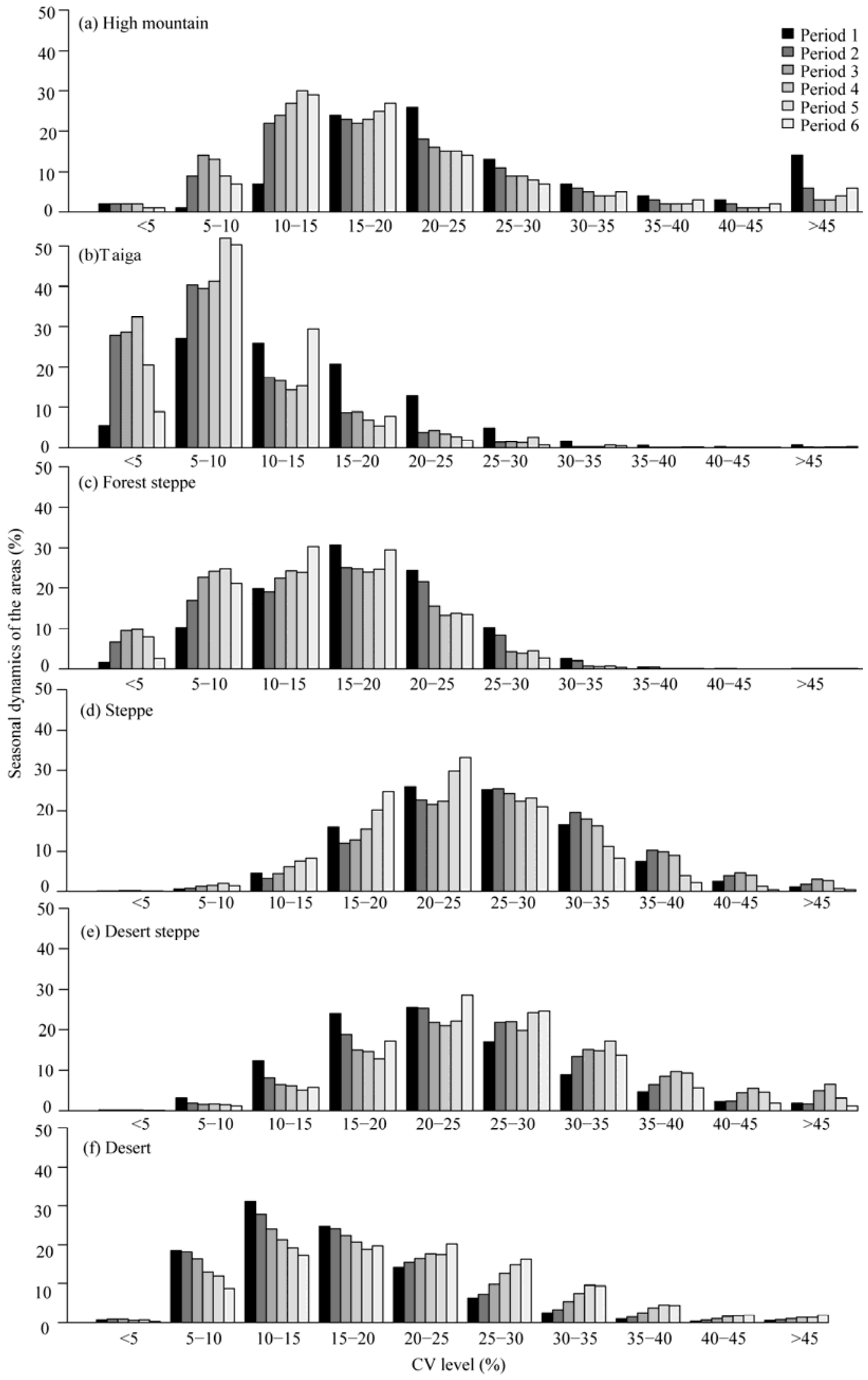

Fig. 8 Seasonal dynamics of the areas for NDVI's CV levels among different natural zones 
grasslands and old fields of North America, whereas the lowest variation was found in forests (Knapp and Smith, 2001). On the Mongolian plateau, the highest CV of ANPP was found in the low precipitation regions, conversely, low variation of ANPP was observed in relatively high precipitation regions (Bai et al., 2008). Moreover, in a natural ecosystem of the northeast region of Brazil, the highest intra-annual CV of NDVI occurred in dry periods and the lowest CV in wet seasons (Barbosa et al., 2006). In China the highest inter-annual CV of NDVI was found in the desert region and lowest CV in forests (Fang et al., 2001).

Our results generally agreed with the results of Fang et al. (2001) and Knapp and Smith (2001), since the taiga zone in our study was equivalent to their forested area. However, there was a contradiction. In the study by Fang et al. (2001) the desert had higher variation of NDVI than all other natural zones in China. On the contrary, our study for Mongolia found that the desert zone had lower variation in vegetation cover than the desert steppe and steppe zones, even though the desert received much less precipitation than the others. We attribute this to more sparse vegetation in the desert than the desert steppe, while the desert steppe may have been lumped together in the largescale survey by Fang et al. (2001). Overall, our results confirmed that the lowest CV of NDVI could occur during wet periods of growing season or in high precipitation regions, while the highest CV of NDVI could occur during dry periods and in low precipitation regions.

Our study identified that the south-eastern steppe and desert steppe of Mongolia were the hotspot of inter-annual NDVI variation. This result was in general agreement with other satellite-based studies. The desert steppe was very vulnerable to desertification (Lin et al., 2006; Batbold and Natsagdorj, 2013) and the steppe was a hotspot of rapid biomass reduction (Liu et al., 2013). A widespread decline of NDVI has been observed for the period of 1988-2008 in the transition zone between steppe and desert steppe of Mongolia (Hilker et al., 2013), while NDVI increased in spring but decreased in summer during the period of 1982-2011 for the Mongolian Plateau, which included Mongolia and Inner Mongolia (Zhao et al., 2014). Our ground-based data and satellite-based data both sup- ported the importance of climatic variables, namely precipitation. The annual mean temperature has increased by $2.14^{\circ} \mathrm{C}$ in the last 70 years in Mongolia (Dagvadorj et al., 2009), leading to greater loss of moisture due to evapotranspiration. Experimental warming studies in a northern Mongolian steppe demonstrated that warming in interaction with livestock grazing greatly affected flowering time and flower production of many dominant species (Liancourt et al., 2012; Spence et al., 2014). Vulnerability of the Mongolian steppe ecosystems to climate change documented in these studies was also supported by our results.

Although climatic variables were shown to be the most important factors, they may not be the only factors contributing to the variation of vegetation cover. Increased livestock grazing is also an issue in Mongolia. According to data from the National Statistical Office of Mongolia, the proportion of goats in the total livestock population and the number of goats dramatically increased from $20.6 \%\left(5.2 \times 10^{6}\right)$ in 1991 , $34.0 \%\left(10.3 \times 10^{6}\right)$ in 2000 and to $42.9 \%\left(17.6 \times 10^{6}\right)$ in 2012 in the Mongolia (NSO, 2013). At the end of our study, the sheep and goats made up $87.3 \%$ of total $4.09 \times 10^{7}$ of livestock population in the country in 2012. In the region (Dundgobi, Dornogobi, Gobisumber, Suhkbaatar and Dornod provinces) that we called the hotspot of NDVI variation, the fluctuations of total number of livestock population were relatively stable between 1970 and $1992\left(3.9 \times 10^{6}-4.6 \times 10^{6}\right.$; with range of $\left.0.7 \times 10^{6}\right)$. However, for the period of 1993-2012, not only the number of livestock increased, but also the inter-annual variability in numbers has increased by as much as 4 times (3.7 $\times 10^{6}-6.7 \times 10^{6}$, with range of $2.9 \times 10^{6}$; NSO, 2013). The livestock population fluctuation was mainly influenced by extreme climatic conditions including severe cold and drought (Tachiiri et al., 2008; Sternberg, 2010; Sternberg et al., 2011), which in turn affected the rangeland productivity, contributing to variation in NDVI (large-scale die-out is usually followed by rangeland regeneration). In addition, there are other anthropogenic and socio-economic stressors that are rising in recent years. These include large-scale mining, urbanization and infrastructure development, as well as changes in movement patterns and more sed- 
entary lifestyle of local herders (Erdenebaatar, 1996; Fernandez- Gimenez et al., 2006). Our results support the findings of other studies that changing climate and political and socio-economic shift in Mongolia in 1990s may have made the steppe or desert steppe ecosystems more vulnerable due to changes in livestock population size and herd structure.

Moreover, the eastern steppe (grassland) provides very important habitats for wildlife, such as the dominant species of Mongolian gazelle (Procapra gutturosa; Ito et al., 2006; Mueller et al., 2008). Its population size was estimated between $8 \times 10^{5}$ and $9 \times 10^{5}$ gazelles (10-11 gazelles $/ \mathrm{km}^{2}$ ) over an area of $8 \times 10^{4}$ $\mathrm{km}^{2}$ (Olson et al., 2005). And the current distribution of Mongolian gazelle (Leimgruber et al., 2001) is largely included in the hotspot area of NDVI variation identified in our study. Movements of this highly mobile ungulate species span over a very wide range $\left(1.4 \times 10^{4}-3.2 \times 10^{4} \mathrm{~km}^{2}\right.$ annually; Olson et al., 2010) and track shifts in primary productivity across the steppe. Their calving grounds have the highest NDVI value during periods of use by gazelles (Leimgruber et al., 2001) and sheer size of this nomadic herd can affect the variability of vegetation cover. In addition, some rodent species such as the Brandt's vole (Microtus brandtii) and Mongolian gerbil (Meriones unguiculatus) are broadly distributed in the short-grass steppe and are considered pests, particularly during population outbreaks. The Brandt's vole population outbreak has increased in frequency since 1970 from 1 every 7 years to 1 every 3 to 5 years in Inner Mongolia (Zhang et al., 2003). In Inner Mongolian Plateau, it has been found that each vole can consume $40 \mathrm{~g}$ of fresh plant material per day. In high-density years with up to 1,384 individuals/ $/ \mathrm{hm}^{2}, 15 \%-44 \%$ of grass production can be used by voles (Zhong et al., 1999; Kang et al., 2007). It could only be worse in Mongolia where the most of the range of this species is included. Among the insects, grasshoppers have a particularly high impact on steppe vegetation, especially in the year of outbreak (Latchininsky, 1997; Kang et al., 2007). Overgrazed pasture grasslands are a subject to grasshopper depredation (Latchininsky, 1995). The herbivore species with population outbreaks such as the Brandt's vole and grasshoppers could contribute to the inter-annual vegetation variability in the grassland.
Climate change, increased livestock grazing and competition with other wildlife, other socio-economic shifts and outbreaks of pest species are a combination of factors leading to spatial and temporal variability of vegetation cover. In the region with high variation of vegetation cover, it is a challenge to apply any natural resource management and to predict ANPP. In Mongolia, so far there has been no rangeland management policy that takes the highly variable inter-annual pattern into account. Our study showed that much of the steppe and desert steppe areas were subject to inter-annual variability (high CV) in NDVI, depending on amount, geographical distribution and variation of precipitation. Although Mongolian nomadic herders have dealt with such unpredictability for millennia by frequently moving with their herd, several recent unprecedented circumstances have emerged as a formidable challenge. First, the number of domestic livestock has reached unprecedented numbers in recent years (NSO, 2013), while the traditional knowledge of pastoral animal husbandry is being lost with the new generation of herders. Second, climate change has been more intense than the world average. Although there was no significant trend in mean annual precipitation, the mean annual temperature has increased by $2.14^{\circ} \mathrm{C}$ in the last 70 years for Mongolia (Dagvadorj et al., 2009). Moreover, the number of extreme events and intense rains have increased (Marin, 2010), making it even more variable and unpredictable for herders. Third, unless there is a nation-wide emergency, the land is managed at the administrative unit levels (province's level), which have become increasingly fragmented since 1920s. Such fragmented management scenario leaves some of the administrative units with nothing but highly variable rangelands while some other units have highly predictable habitats. This divided situation calls for re-organization of administrative units or for pastoral practices in the country that would allow herders to move with their animals longitudinally from south to north, similar to the situation pre-1920s, an idea that has been seriously considered at the policy-makers' level (FernandezGimenez, 2002; Johnson et al., 2006). Our study results confirm that such nation-wide rangeland management practice is increasingly needed for sustainability of pastoral nomadism. 


\section{Conclusions}

The taiga and forest steppe were relatively stable for vegetation cover because of a relatively high amount of precipitation and relative constancy of forest ecosystems. The taiga region was completely different from the other natural zones: more than $60 \%$ of the area for the taiga region had very low variation (0-10\%) during the summer. The percent of the area that is $>15 \%$ CV of NDVI in the taiga and more than $20 \%$ in the forest steppe and high mountains decreased through the summer. In the desert zone, the areas that had $0-20 \%$ variation for vegetation cover decreased during the summer, whereas the areas with more than $20 \%$ variation of vegetation cover increased during the summer. The highest CV of vegetation cover occurred frequently in the steppe and desert steppe, because of variation of precipitation, and the percent of area that had relatively high variation (more than 30\%) increased in mid-summer. The percent of the area and its seasonal changes in such a CV level were very similar in these zones, except for seasonal changes of the areas that had CVs of $0-20 \%$. Such variability of vegetation cover was considered to be a formidable management challenge.

Ground-based data showed that spatial and temporal distributions of vegetation cover variation were highly dependent on the amount, distribution and CV of precipitation. The CVs of NDVI in periods 5 and 6 were highly and positively affected by the annual and July precipitation, while a highly negative relationship was found with the MAP for the whole of Mongolia.

In summary, the CV of NDVI or ANPP variation was mainly controlled by the temporal and spatial distribution of precipitation. That is, the lowest $\mathrm{CV}$ of NDVI can occur during the wet season and in regions with high precipitation, whereas the highest CV of NDVI can occur during dry periods and/or in regions with low precipitation. Even though the desert received less precipitation than other natural zones, it has relatively lower variation than the steppe and desert steppe because of its sparse vegetation.

\section{Acknowledgments}

This study was funded by the Green Gold Phase IV Project of the Swiss Development Cooperation Agency. A partial support for this study has also been provided by the Asia Research Center,
Mongolia. We thank Mr. James KAEMMERER, Instructor at the Educational Advising Resource Center (Education USA) in Ulaanbaatar, for professional English editing.

\section{References}

Bai Y F, Wu J G, Xing Q M, et al. 2008. Primary production and rain use efficiency across a precipitation gradient on the Mongolia plateau. Ecology, 89(8): 2140-2153.

Barbosa H A, Huete A R, Baethgen W E. 2006. A 20-year study of NDVI variability over the Northeast Region of Brazil. Journal of Arid Environments, 67(2): 288-307.

Batbold A, Natsagdorj L. 2013. Assessment of Mongolian desertification status using vegetation indices. In: Sarantuya G, Gomboluudev P. Proceeding of Regional Climate Change and Desertification. Mandalgobi: ADMON, 14-20.

Campos-Arceiz A, Takatsuki S, Lhagvasuren B. 2004. Food overlap between Mongolian gazelles and livestock in Omnogobi, southern Mongolia. Ecological Research, 19(4): 455-460.

Dagvadorj D, Natsagdorj L, Dorjpurev J, et al. 2009. MARCC 2009: Mongolia assessment report on climate change 2009. Ulaanbaatar: Ministry of Nature, Environment and Tourism, 39-40.

Dash D. 2000. Landscape-Ecological Problems of Mongolia. Ulaanbaatar: Urlakh Erdem, 21-54.

Erdenebaatar B. 1996. Socio-economic aspects of the pastoral movement patterns of Mongolian herders. In: Humphrey C, Sneath D. Culture and Environment in Inner Asia. Cambridge: The White Horse Press, 58-110.

Fang J, Piao S, Tang Z, et al. 2001. Inter-annual variability in net primary production and precipitation. Science, 293(5536): 1723.

Fernandez-Gimenez M E. 2002. Spatial and social boundaries and the paradox of pastoral land tenure: a case study from postsocialist Mongolia. Human Ecology, 30(1): 49-78.

Fernandez-Gimenez M E. 2006. Land use and land tenure in Mongolia: A brief history and current issues. Rangelands of Central Asia: Proceedings of the Conference on Transformations, Issues, and Future Challenges. USDA Forest Service Proceedings, 30-36.

Hilker T, Natsagdorj E, Waring R H, et al. 2013. Satellite observed widespread decline in Mongolian grasslands largely due to overgrazing. Global Change Biology, 20(2): 418-428.

Hirano A, Toriyama K, Komiyama H. 2006. Spatiotemporal characterization of Mongolian grassland based on vegetation trend analysis. Asian Association on Remote Sensing-Proceedings, A2-A8.

Ito T Y, Miura N, Lhagvasuren B, et al. 2005. Preliminary evidence of a barrier effect of a railroad on the migration of Mongolian gazelles. Conservation Biology, 19(3): 945-948.

Johnson D A, Sheehy D P, Miller D, et al. 2006. Mongolian rangelands in transition. Secheresse, 17(1): 133-141.

Kang L, Han X, Zhang Z, et al. 2007. Grassland ecosystems in China: review of current knowledge and research advancement. Philosophical Transactions of the Royal Society B: Biological Sciences, 362(1842): 997-1008.

Karnieli A, Bayasgalan M, Bayarjargal Y, et al. 2006. Comments on the use of the vegetation health index over Mongolia. International Journal of Remote Sensing, 27(10): 2017-2024. 
Knapp A K, Smith M D. 2001. Variation among biomes in temporal dynamics of aboveground primary production. Science, 291(5503): 481-484.

Latchininsky A V. 1995. Grasshopper problems in Yacutia (Eastern siberia, Russia) grasslands. Journal of Orthoptera Research, 29-34.

Latchininsky A V. 1997. Grasshopper control in Siberia: strategies and perspectives. New Strategies in Locust Control, 493-502.

Leimgruber P, McShea W J, Brookes C J, et al. 2001. Spatial patterns in relative primary productivity and gazelle migration in the Eastern Steppes of Mongolia. Biological Conservation, 102(2): 205-212.

Liancourt P, Spence L A, Boldgiv B, et al. 2012. Vulnerability of the northern Mongolian steppe to climate change: insights from flower production and phenology. Ecology, 93(4): 815-824.

Lin M L, Chu C M, Shi J Y, et al. 2006. Assessment and monitoring of desertification using satellite imagery of MODIS in East Asia. In: Kuligowski R J, Parihar J S, Saito G. Proceedings of SPIE 6411, Agriculture and Hydrology Applications of Remote Sensing, 641123: 1-9

Liu Y Y, Evans J P, McCabe M F, et al. 2013. Changing climate and overgrazing are decimating Mongolian steppes. PLoS One, 8(2): e57599.

Marin A. 2010. Riders under storms: contributions of nomadic herders' observations to analysing climate change in Mongolia. Global Environmental Change, 20(1): 162-176.

Mueller T, Olson K A, Fuller T K, et al. 2008. In search of forage: predicting dynamic habitats of Mongolian gazelles using satellitebased estimates of vegetation productivity. Journal of Applied Ecology, 45(2): 649-658.

Nicholson S E, Davenport M L, Malo A R. 1990. A comparison of the vegetation response to rainfall in the Sahel and East Africa, using normalized difference vegetation index from NOAA AVHRR. Climatic Change, 17(2-3): 209-241.

NSO. 2013. Mongolian Statistical Year Book. Ulaanbaatar: National Statistics Office of Mongolia.

Oesterheld M, Loreti J, Semmartin M, et al. 2001. Inter-annual variation in primary production of a semi-arid grassland related to previousyear production. Journal of Vegetation Science, 12(1): 137-142.

Oindo B O, Skidmore A K. 2002. Interannual variability of NDVI and species richness in Kenya. International Journal of Remote Sensing, 23(2): 285-298.

Olson K A, Fuller T K, Schaller G B, et al. 2005. Estimating the population density of Mongolian gazelles Procapra gutturosa by driving long-distance transects. Oryx, 39(2): 164-169.

Olson K A, Fuller T K, Mueller T, et al. 2010. Annual movements of
Mongolian gazelles: nomads in the Eastern Steppe. Journal of Arid Environments, 74(11): 1435-1442.

Sanders H L, Hessler R R. 1969. Ecology of the deep-sea benthos. Science, 163: 1419.

Spence L A, Liancourt P, Boldgiv B, et al. 2014. Climate change and grazing interact to alter flowering patterns in the Mongolian steppe. Oecologia, 175(1): 251-260.

Sternberg T. 2010. Unravelling Mongolia's extreme winter disaster of 2010. Nomadic Peoples, 14(1): 72-86.

Sternberg T, Thomas D, Middleton N. 2011. Drought dynamics on the Mongolian steppe, 1970-2006. International Journal of Climatology, 31(12): 1823-1830.

Tachiiri K, Shinoda M, Klinkenberg B, et al. 2008. Assessing Mongolian snow disaster risk using livestock and satellite data. Journal of Arid Environments, 72(12): 2251-2263.

Tilman D. 1996. Biodiversity: population versus ecosystem stability. Ecology, 77(2): 350-363.

Von Wehrden H, Wesche K. 2007. Relationships between climate, productivity and vegetation in southern Mongolian drylands. Basic and Applied Dryland Research, 1(2): 100-120.

Wang J, Rich P M, Price K P. 2003. Temporal responses of NDVI to precipitation and temperature in the central Great Plains, USA. International Journal of Remote Sensing, 24(11): 2345-2364.

Webb W L, Lauenroth W K, Szarek S R, et al. 1983. Primary production and abiotic controls in forests, grasslands, and desert ecosystems in the United States. Ecology, 64(1): 134-151.

Xin Z, Xu J, Zheng W. 2008. Spatiotemporal variations of vegetation cover on the Chinese Loess Plateau (1981-2006): impacts of climate changes and human activities. Science in China Series D: Earth Sciences, 51(1): 67-78.

Yoshihara Y, Ito T Y, Lhagvasuren B, et al. 2008. A comparison of food resources used by Mongolian gazelles and sympatric livestock in three areas in Mongolia. Journal of Arid Environments, 72(1): 48-55.

Zhang Z, Pech R, Davis S, et al. 2003. Extrinsic and intrinsic factors determine the eruptive dynamics of Brandt's voles Microtus brandti in Inner Mongolia, China. Oikos, 100(2): 299-310.

Zhao X, Hu H F, Shen H H, et al. 2014. Satellite-indicated long-term vegetation changes and their drivers on the Mongolian Plateau. Landscape Ecology, doi: 10.1007/s10980-014-0095-y.

Zhong W, Wang M, Wan X. 1999. Ecological management of Brandt's vole (Microtus brandti) in Inner Mongolia, China. Ecologically-based Rodent Management. ACIAR Monograph, 59: 119-214. 